\title{
A NAVEGAÇÃO DOS ALUNOS NOS FÓRUNS VIRTUAIS E A APRENDIZAGEM COLABORATIVA
}

\author{
E. S. JUNQUEIRA* \\ Universidade Federal do Ceará \\ eduardoj@virtual.ufc.br*
}

Artigo submetido 29/05/2017 e aceito 28/01/2019

DOI: $10.15628 /$ holos.2019.5957

\section{RESUMO}

Estudo de mapeamento da navegação em conteúdos hipertextuais e ambiente virtual de aprendizagem. O objetivo foi compreender como alunos de cursos a distância navegavam e como isso contribuía ou interferia na aprendizagem. Os resultados indicaram o fórum virtual como ponto central das ações, onde ocorreram interações descritas como navegação não linear com skimming, navegação não linear com leitura detalhada, navegação para compartilhamento e acesso de arquivos e navegação intercalada no fórum, aulas e internet. Ocorreu interação dos alunos, configurando ações de colaboração e aprendizagem, ampliando as fronteiras dos conteúdos das disciplinas e do papel do aluno como um produtor de saberes.

PALAVRAS-CHAVE: Navegação, Hipertexto, Aprendizagem colaborativa, Educação a Distância.

\section{Students' navigation on online forums and collaborative learning}

\begin{abstract}
The study mapped navigation in hypertextual contents and virtual learning environment. The goal was to understand how students from distance learning courses navigated and how this contributed or interfered with learning. The results indicated the virtual forum as the focal point of the actions, where interactions
\end{abstract} nonlinear navigation with detailed reading, navigation for sharing and file access and navigation intercalated in the forum, classes and internet occurred. Students interacted, setting up collaborative and learning actions, expanding the boundaries of the contents of the subjects and the student's role as a producer of knowledge. 


\section{INTRODUÇÃO}

A internet é constituída por um universo caótico de redes, nós e links de variados tipos e formas de informação agregados no hipertexto, que pode ser acessado em uma vasta combinação de trajetórias delineadas pelos usuários que constroem trilhas de navegação e interagem com conteúdos e com outros usuários. O acesso, a troca e a produção de informações na internet possuem um enorme potencial para ampliar os processos educacionais contemporâneos, mas esse potencial precisa ser melhor documentado e compreendido. Este artigo apresenta e analisa dados de um estudo que mapeou a navegação hipertextual de alunos de cursos de licenciatura semipresenciais de matemática e letras-português no contexto dos momentos de aprendizagem desses sujeitos. O mapeamento partiu das ações dos alunos no Ambiente Virtual de Aprendizagem (AVA) e ampliou-se para a navegação por outros espaços da internet e pelas telas e ferramentas de programas e aplicativos de computador. A documentação da navegação dos alunos foi realizada através da gravação da navegação em tela e de relatos descritivos comentados pelos próprios sujeitos. O objetivo foi conhecer, a partir da visão dos alunos, como eles navegam no AVA e na internet em seus momentos de estudo e aprendizagem.

Mais especificamente, este artigo se deterá sobre a navegação dos alunos no espaço dos fóruns virtuais de aprendizagem do AVA. O uso de fóruns virtuais em cursos semipresenciais e em chamados cursos à distância ou online tem se tornado prática rotineira (ARTIGO DO AUTOR). Em certos aspectos, o uso dos fóruns se assemelha à prática das trocas que se constituem no espaço da sala de aula tradicional, pois permite que os participantes exponham e compartilhem ideias, dúvidas e questões e possam receber retorno e orientações do professor/tutor no processo de construção de conhecimentos. Na virtualidade, o fórum possibilita a realização desse processo a despeito de distâncias geográficas, e propicia a documentação das trocas e o compartilhamento de materiais diversos, como imagens, web links de documentos e vídeos, dentre outros. O fórum virtual é, dessa forma, componente fundamental nos processos de aprendizagem nas novas modalidades educativas via internet.

\section{NAVEGAÇÃO HIPERTEXTUAL}

Braga (2005, p. 147) explica que "o hipertexto é completamente diferente do texto impresso, uma vez que só oferece ao leitor os bits e pedaços de informação, permitindo potenciais trajetórias de loop sem uma narrativa ou eixo argumentativo em uma sequência". Isso significa que o "usuário navega através dos nós da rede de uma forma totalmente imprevisível, muitas vezes até para si mesmo" (LEÃO, 2001, p. 57). Apesar da natureza caótica da navegação, autores também apontam para o fato de que o processo de navegação pode ser influenciado pelo design da hipermídia, conforme apontado por Teixeira (2005, p.1):

[...] quando navegamos na internet, estamos continuamente a fazer escolhas. Nós escolhemos uma ligação em vez de outra, não só com base em nosso objetivo de chegar a um ponto atrás dele, mas também com base na maneira como link foi exibido na interface do designer. Em um ambiente de abundância de informação, que sofrem com a falta de 
atenção, um projeto de interface que capta a atenção do usuário é fundamental para o seu sucesso (Teixeira, 2005, p.1).

Murray (2003), ao abordar as narrativas em games, nos permite realizar diversas aproximações com a navegação hipertextual aqui tratada. Segundo a autora, nos games (bem como na internet) há várias possibilidades para os percursos realizados pelos usuários, que seguem por caminhos distintos a cada partida (ou navegação, no caso da internet) sem necessariamente alcançar o mesmo desfecho. Tais trajetórias fluidas, que se constituem no escopo do jogo ou da internet, articulam-se a partir de dois elementos-chave: a estrutura maleável do jogo criada pelos designers (incluindo cenários, personagens e ações) e as decisões e ações empreendidas pelos jogadores ao longo da partida, resultando na co-construção de narrativas fluídas. A fluidez das narrativas propostas por Murray (2003) articula-se com as ações do usuário/navegador/jogador ao longo da co-construção dessas narrativas.

A navegação hipermodal compreende, portanto, o movimento relativamente aberto e pouco previsível dos leitores-usuários através do espaço, articulado previamente pelos designers e vivenciado pelo usuário, formado de nós e outros tipos de conexões entre eles, os links (Ulbricht apud Padovani; Moura, 2008). A navegação ocorre em geral a partir da busca de informações e alvos pelo usuário e pode levar à construção do conhecimento, não se restringindo a uma mera ação mecânica. Ao percorrer e (re)construir hipertextos, o usuário pode fazer uso das seguintes estratégias de navegação (Centro et al. apud Padovani; Moura, 2008):

Navegação - o acesso a um conjunto de nós interconectados por ligações de ativação;

Skimming - o ato de cobrir superficialmente uma extensa área de informações e nós na tela;

Busca - o ato de encontrar um não alvo previamente determinado;

Exploração - a livre busca de informações disponíveis em uma rede ou sistema;

Errância - a navegação aleatória, não estruturada.

Santaella (2004) aponta peculiaridades no modo de ler (navegar) em suportes e plataformas digitais e estabelece a tipologia do leitor imersivo, virtual, que surgiu com o advento dos novos espaços da virtualidade (o termo leitor é aqui usado de forma similar ao termo usuário). O leitor imersivo realiza uma leitura dinâmica, não sequencial, não manuseável dos hipertextos. Há, no entanto, "convivência e reciprocidade" (Santaella, 2004, p. 19) entre o leitor imersivo e outros dois tipos propostos pela autora, visto que não são excludentes. São eles o leitor contemplativo ou meditativo, da era do surgimento do livro e da imagem expositiva (de objetos manuseáveis, duráveis). É um leitor solitário, individual. Segundo a autora, sua leitura é silenciosa e sequencial, o que exige concentração por parte do leitor. A segunda categorização refere-se ao leitor movente, dinâmico, da época do surgimento dos grandes centros urbanos e da efervescência dos jornais, das revistas, do cinema e da fotografia. É um leitor apressado, que lê através de sinais, signos e luzes, selecionando o que lhe interessa, passando os olhos aos saltos, adivinhando o contexto.

A navegação pelos hipertextos não se restringe à busca de informações e conteúdos de caráter educacional pelo aluno. Constitui-se em rede, potencializado a interação e comunicação do 
aluno em tempo real ou de forma assíncrona com outros, constituindo, dessa forma, ricos processos de trocas e compartilhamentos diversos. Essa navegação, no contexto da aprendizagem, é caracterizada pelas ações dos alunos no AVA e para além dele (em diversos web sites na internet, por exemplo) com a finalidade de realizar as atividades propostas no curso e outras associadas ao curso (por exemplo, a troca de ideias e o compartilhamento de materiais com colegas de curso). Esse processo de navegação no AVA e na internet pode tomar variadas formas, modos e trajetórias geralmente associados às habilidades, interesses e disposições do aluno - abrangendo uma infinidade de conteúdos temáticos nas diversas linguagens (texto escrito, vídeos, infográficos, imagens, podcasts, etc.), a partir das múltiplas trajetórias abertas pelos hipertextos.

A navegação online, seja na internet ou em ambientes fechados, como um web site com diversas rotas de acesso e diversas seções e conteúdos, pode gerar desorientação espacial do navegante (Padovani \& Moura, 2008) e ocasionar sobrecarga cognitiva (Destefano \& Lefreve, 2007), pois demanda esforço adicional do aluno para processar diversas informações e realizar múltiplas tarefas. É possível ocorrer também o fenômeno da digressão embutida (PADOVANI; Moura, 2008) quando a própria rede incita a exploração de diversas trilhas e opções, levando o usuário a perder o foco da navegação, ainda que apenas temporariamente. São ocorrências não desprezíveis, tendose em vista que alunos, particularmente aqueles envolvidos em cursos online ou a distância, têm se aventurado em buscar conteúdos associados aos seus estudos para além daqueles disponibilizados pela instituição de ensino no respectivo AVA (ARTIGO DO AUTOR).

A navegação online, seja na internet ou em ambientes fechados, como um web site com diversas rotas de acesso e diversas seções e conteúdos, pode gerar desorientação espacial do navegante (Padovani; Moura, 2008) e ocasionar sobrecarga cognitiva (Destefano \& Lefreve, 2007), pois demanda esforço adicional do aluno para processar diversas informações e realizar múltiplas tarefas. É possível ocorrer também o fenômeno da digressão embutida (Padovani; Moura, 2008) quando a própria rede incita a exploração de diversas trilhas e opções, levando o usuário a perder o foco da navegação, ainda que apenas temporariamente. São ocorrências não desprezíveis, tendose em vista que alunos, particularmente aqueles envolvidos em cursos online ou a distância, têm se aventurado em buscar conteúdos associados aos seus estudos para além daqueles disponibilizados pela instituição de ensino no respectivo AVA (ARTIGO DO AUTOR).

\section{AMBIENTE VIRTUAL DE APRENDIZAGEM E FÓRUM}

O ambiente virtual de aprendizagem no qual esse estudo foi conduzido é utilizado nos cursos de educação a distância de uma universidade federal da região nordeste do país. O AVA centraliza as atividades didáticas e de comunicação e de interação entre os participantes. O professor ou tutor podem disponibilizar informações sobre a disciplina (por exemplo, ementa, agenda e bibliografia); publicar materiais de apoio e aulas (como elementos hipermidiáticos, como imagens, vídeos, objetos interativos, infográficos e jogos feitos na plataforma Flash); criar sessões de web conferência e bate-papo; participar de fóruns; receber trabalhos, comentá-los e divulgar as notas; além de trocar mensagens com os participantes. A centralidade do AVA está na seção Aulas, que reúne todo o conteúdo disciplinar desenvolvido pelo professor responsável. Esse conteúdo, com forte 
predominância textual-verbal, é editado no formato de páginas web, dividido entre diversas "aulas" (blocos de conteúdo associados a atividades para aprendizagem) a serem navegadas pelo aluno ao longo da disciplina.

O fórum virtual de aprendizagem se constitui como um espaço de interação muito difundido na internet, e principalmente nos AVAs, promovendo o contato com outras pessoas para trocas assíncronas de mensagens permitindo a visualização a todos os participantes. Na educação online, o fórum destina-se ao compartilhamento de saberes e de experiências entre os alunos, podendo potencializar o conhecimento e o aprendizado, além de permitir que se tornem desenvolvedores de conteúdos colaborativos, a partir das leituras e reflexões acerca da temática em estudo. O AVA disponibiliza uma lista de todos os fóruns da disciplina cursada pelo aluno, com suas respectivas datas de início e término, indicando a postagem mais recente e o número de postagens realizadas até dado momento.

Para que o aluno possa criar uma nova postagem, o fórum dispõe de um editor simples de texto, que consiste em uma caixa para digitação de até 2.000 caracteres por mensagem. Além disso, o aluno pode visualizar, na mesma página, a descrição do fórum, que muitas vezes contém o enunciado da atividade. É possível também anexar documentos diversos. $O$ aluno pode também responder a uma mensagem já existente através do botão "Responder", disponível em cada mensagem. $O$ sistema também permite ao aluno excluir ou editar as suas próprias mensagens. $O$ fórum do AVA possui a clássica interface de fórum virtual: As mensagens aparecem em blocos e incluem a data e hora em que foram publicadas, além da identificação do autor através do nome ou apelido e o avatar (uma imagem associada ao aluno).

A interação através da troca de mensagens de forma assíncrona nos fóruns constitui elemento central na aprendizagem dos alunos, ao permitir as trocas e a colaboração entre eles. Primo (2008) articulou o conceito de interação mútua, que consiste na construção de um conjunto de ações nas quais os participantes recriam e renovam uma informação dada, não se podendo prever o resultado que será gerado, já que é resultado das relações interdependentes que ocorrem entre os sujeitos.

\section{APRENDIZAGEM COLABORATIVA}

De acordo com Dillenbourg et al. (1996, p. 21, tradução nossa), a "colaboração é uma estrutura social na qual duas ou mais pessoas interagem entre si e, em algumas circunstâncias, alguns tipos de interação produzem resultados positivos", ou seja, essas interações podem resultar em um avanço na aprendizagem dos participantes. No presente estudo foram adotadas, para fins de análise dos dados coletados, as perspectivas socioconstrutivista (a partir de Piaget) e sociocultural (a partir das proposições teóricas de Vygotsky) articuladas nos estudos de Dillenbourgh et al. (1996) sobre a aprendizagem colaborativa.

A aprendizagem colaborativa constitui-se nas trocas entre dois ou mais alunos. Essas trocas podem ter um caráter heterogêneo, ou seja, elas abarcam diferentes níveis de conhecimento e diferentes formas de formular esse conhecimento dos alunos. Essa troca heterogênea constitui um elemento positivo para a aprendizagem resultante. Segundo as formulações de Piaget, estão 
intrinsecamente relacionadas ao processo de assimilação de novos conhecimentos. Na perspectiva de Vygotsky (2003), configuram a efetivação da zona de desenvolvimento proximal (DAMIANI, 2008). Segundo Dillenbourg et al. (1996, p. 5), "o mecanismo pelo qual se dá a participação na solução conjunta de um problema pode levar a uma mudança na compreensão do problema". Os estudos de Dillenbourgh reportam aspectos positivos da comunicação mediada por computador - na qual os fóruns do AVA se enquadram - pois "a comunicação assíncrona baseada em textos permite tempo de reflexão aos alunos e possibilita aos alunos menos confidentes a aprender observando a conversa entre outros colegas" (Dillenbourgh et al, 1996, p. 15).

Dillenbourgh e os demais autores sintetizaram categorias, utilizadas em diversos estudos para analisar interações com vistas à aprendizagem, articuladas como pares de conceitos bipolares: (1) social/cognitivo, (2) cognitivo/metacognitivo, e (3) tarefa/comunicação. Para os fins desse estudo, adotaremos a terceira categoria - tarefa/comunicação - uma vez que os fóruns analisados são desenvolvidos a partir de tarefas objetivas propostas pelo professor e o material documentado nos permite analisar o processo de trocas comunicativas visando solucionar a tarefa estabelecida, abrangendo, dessa forma, as trocas entre os alunos no contexto da tarefa a ser realizada.

\section{DOCUMENTAÇÃO DA NAVEGAÇÃO HIPERMODAL}

O presente estudo documentou o processo de navegação virtual durante atividades de estudo no computador de 12 alunos dos cursos semipresenciais de matemática e letras-português de uma universidade federal. A documentação abrangeu a captura dinâmica de diversas telas dessa navegação, incluindo páginas do AVA, páginas na internet e softwares diversos em uso pelos alunos. Um pré-teste foi realizado com quatro estudantes no ano passado em uma sala adaptada no polo presencial do curso em uma cidade da região metropolitana em que a universidade está localizada.

O procedimento de coleta de dados consistiu em quatro atividades subsequentes que duraram 10 minutos cada, com cada aluno. Os alunos foram convidados a navegar para realizar atividades de estudo do curso. O programa CamtasiaStudio foi utilizado para a documentação da navegação em tela dos alunos, ou seja, seus movimentos incluindo saltos (de um ponto a outro da tela ou da página ou entre telas do computador), regressões e avanços em uma página ou entre diversas páginas do AVA e da internet e em programas disponíveis no computador. Esta documentação ocorreu quando os alunos estavam ativamente engajados nas atividades do curso durante o semestre letivo.

Nas duas primeiras atividades de navegação, o aluno ficou sozinho no laboratório, enquanto a navegação foi documentada pelo CamtasiaStudio. Os alunos podiam navegar como eles preferiam, de forma livre, para realizar atividades de estudo. Para as duas últimas atividades o coordenador do estudo posicionou-se ao lado dos estudantes para observá-los. O pesquisador enfatizou a eles a necessidade de se concentrarem na tarefa em desenvolvimento. Notas detalhadas sobre as principais ocorrências ao longo do processo de coleta de dados foram tomadas.

Ao final da sessão de documentação, o pesquisador conduziu entrevista semi-estruturada com os alunos para compreender as principais ocorrências ao longo da navegação. Perguntas de sondagem incluíram informações sobre a lógica do aluno envolvida na navegação documentada, os 
objetivos do aluno, as dificuldades encontradas pelo aluno ao longo da navegação e a opinião do aluno sobre sua aprendizagem nesses momentos.

Relatórios descritivos detalhados sobre a navegação e as respostas dos alunos foram escritos. Foram considerados, principalmente: a) páginas acessadas pelos alunos, b) suas áreas de interesse dentro dessas páginas, c) ocorrência de navegação (interligando nós pela ativação de links), buscas (encontrar um alvo preestabelecido); exploração (em busca de informações disponíveis na internet) e ações vagas (navegação aleatória); d) a sequência de navegação em cada aluno; e) interações entre alunos e tutores.

Foi realizada uma análise em busca das ocorrências descritas anteriormente ao longo de cada sessão de navegação. Ocorrências foram comparados em busca de relações e semelhanças que pudessem indicar ações comuns de navegação, bem como diferenças entre os alunos. No tópico seguinte os alunos serão apresentados somente pela letra inicial de seus nomes, tendo suas falas transcritas entre aspas e trechos das anotações dos relatórios de coleta de dados reproduzidos a fim de dar sentido à documentação e às observações realizadas nesse estudo.

\section{NAVEGAÇÃO DOS ALUNOS NO FÓRUM DO AVA}

A análise dos dados indicou que o fórum se constituiu como o ponto central da navegação dos alunos, ou seja, quase todas as atividades de navegação documentadas neste estudo incluíram o fórum. Conforme relatou a aluna $\mathrm{C}$, a participação mais ativa se deu naqueles fóruns cuja disciplina não Ihes era muito familiar, ou seja, em que os alunos enfrentavam dificuldades para compreender os conteúdos curriculares e para realizar as atividades programadas. O mapeamento da navegação hipermodal dos alunos identificou ocorrências principais, além de sub-ocorrências, no fórum do AVA. As categorias de navegação identificadas, detalhadas a seguir, foram:

A) Navegação não linear em formato de skimming (leitura superficial) direcionada pelas necessidades dos alunos ao longo da disciplina. Essa ação foi documentada entre diversos alunos. $\mathrm{O}$ aluno $\mathrm{F}$, por exemplo, afirmou que tinha o hábito de ler postagens realizadas no fórum antes de acessar o conteúdo da aula para ver o que os colegas comentaram. Ele considerava que isso era uma ação útil para uma melhor compreensão do conteúdo debatido na aula. A aluna G afirmou que realizava essa ação no fórum para "esclarecer as dúvidas, discutir sobre as questões. Algum colega lança uma questão e se você souber responder você vai lá e responde".

B) Navegação não linear no fórum, com ocorrências de leitura mais detalhada de algumas postagens. Ocorreram duas modalidades:

- Postagens realizadas pelos colegas de turma. Nesses casos os alunos navegaram utilizando a barra de rolagem do fórum, realizando movimentos ascendentes e descendentes na página ao lerem trechos de textos postados pelos colegas de turma. Essas ações visavam a elaboração de postagens pelos alunos e a comparação entre as diversas postagens realizadas pelos alunos da turma. O Aluno $\mathrm{M}$, por exemplo, realizou diversas ações de skimming no fórum, fixandose na leitura de algumas postagens de colegas de turma. Ele afirmou que costumava navegar pelo fórum a fim de ler e de comparar as respostas/postagens para verificar o que estava certo ou errado 
como, por exemplo, durante a atividade de tradução de frases em latim de disciplina considerada difícil e desafiadora pelos alunos, segundo seu depoimento. O Aluno J, por sua vez, explicou que sua primeira ação de navegação no fórum destinava-se a analisar o enunciado da atividade proposta e que publicava sua postagem somente após refletir sobre o que estava sendo solicitado pelo enunciado da atividade.

- Postagens realizadas pelo tutor da disciplina. Foram identificadas diversas ocorrências de navegação com o objetivo de verificar a ocorrência de postagens do tutor no fórum, seguido de leitura dessas mensagens pelos alunos. O aluno $\mathrm{J}$ deu destaque à postagem do tutor, afirmando que parte significativa da atenção dos alunos era dada a esses conteúdos. $\mathrm{O}$ aluno $\mathrm{X}$ comentou sobre o papel do tutor no fórum, informando que ele monitora e incentiva a participação dos alunos e a troca de conhecimentos.

As ocorrências das categorias relatadas neste tópico também ocorreram nos chamados fóruns livres das disciplinas. Esses servem como um espaço adicional para dirimir dúvidas sobre os conteúdos de forma mais ampla, fugindo do caráter de "resposta à atividade" dos fóruns tradicionais.

C) Navegação no fórum intercalada com navegação nas aulas e na internet. Nesses casos, os alunos navegavam através de movimentos ascendentes e descendentes nas página(s) do fórum, da aula e em diversas páginas web acessadas, utilizando a barra de rolagem. Ao navegar, eles realizavam leituras do tipo skimming, bem como leituras mais detalhadas, essas em geral associadas aos momentos de escrita de comentários no fórum. A seguinte experiência do aluno J ilustrou esta ação documentada entre diversos alunos: Ao elaborar uma resposta para o fórum, J buscou informações adicionais na internet. $O$ aluno relatou que se orientava pelos conteúdos que já haviam sido postados pelos colegas e nas referências divulgadas no fórum para não repeti-las e também para verificar a veracidade das respostas publicadas pelos colegas. J analisava as respostas dos colegas navegando em outras páginas da internet, quando realizava pesquisas de outros conteúdos a fim de verificar se as postagens dos colegas faziam sentido e se estavam de acordo com o tema do fórum. Esse aluno comentou que umas das vantagens dessas ações de navegação era a de que o aluno estudava para responder no fórum e que quem lia e acompanhava as discussões conseguia compreender bem a temática das aulas.

D) Navegação para compartilhamento e acesso de arquivos no fórum. Os dados também revelaram que as ações de navegação dos alunos visavam buscar e compartilhar conteúdos adicionais no fórum para auxiliar os colegas nas resoluções das atividades programadas. Foram documentadas diversas ações nessa categoria, bem como do seu acesso por outros alunos ao navegarem por tais materiais. A aluna $G$ afirmou que os materiais disponibilizados pelos alunos ajudaram bastante em seus estudos durante a disciplina cursada porque, para ela, essas ações criaram mais oportunidades de pesquisa, algo necessário tendo-se em vista que, para eles, as aulas nem sempre abordavam os temas na profundidade desejada e os próprios colegas de turma sentiam necessidade de mais materiais de estudo.

Em suma, os dados indicam as seguintes ocorrências relacionadas à ação dos alunos no fórum do AVA: navegação não linear, direcionada pelos manifestos interesses dos alunos e 
relacionada às dificuldades vivenciadas na disciplina cursada. Disciplinas com maior grau de dificuldade, segundo as vivências dos alunos, registraram maior frequência de navegação no fórum. Navegação do tipo skimming esteve associada à necessidade do aluno em ter um panorama sobre os conteúdos do fórum, ou seja, sobre quem e o que estava sendo postado. Navegação com leitura mais detalhada e seletiva das postagens esteve associada à necessidade do aluno de encontrar respostas para suas dúvidas relacionadas ao conteúdo disciplinar e a escrever e publicar novas postagens no fórum - em resposta aos colegas e para cumprir tarefas demandadas pelo tutor da disciplina. Nos momentos de leitura mais detalhada de postagens dos colegas e de escrita de comentários, a navegação no fórum intercalou ações de navegação na aula e na internet e também incluiu a navegação em arquivos diversos, como os de processadores de textos tipo doc. Em alguns casos essas navegações incluíram o compartilhamento de novos materiais pelos alunos (web sites, textos em formato digital, vídeos), muitos considerados úteis por eles.

Registrou-se também a interrupção na navegação em tela para uso do suporte papel para a escrita de rascunhos. $\mathrm{O}$ grau de dificuldade do aluno na disciplina indicou uma relação com maior frequência de navegação no fórum. Já o tipo de navegação - menos ou mais linear - esteve relacionada ao tipo de fórum - fórum de intercâmbio de ideias ou fórum de pergunta-resposta, respectivamente. Por fim, cabe ressaltar que o caráter de fórum de uma disciplina acadêmica desvincula a navegação dos alunos do aspecto meramente informativo ou recreacional em geral encontrado em outros fóruns da internet. Nos casos documentados, a navegação ocorria em relação com as atividades programadas e com os objetivos de aprendizagem dos alunos ao longo da disciplina.

\section{IMPLICAÇÕES DIDÁTICO-PEDAGÓGICAS A PARTIR DE OCORRÊNCIAS DE NAVEGAÇÃO DOS ALUNOS FÓRUM}

A navegação documentada indicou que os alunos exploram os conteúdos dos colegas (e do tutor, quando disponibilizado) através de skimming, leitura detalhada e acesso a arquivos compartilhados, e postaram seus comentários, em geral em resposta a comentários prévios dos colegas e do tutor. Constituiu-se, dessa forma, uma importante interação entre os alunos nos fóruns, que colaboravam ao longo do processo de aprendizagem. Em alguns fóruns de disciplinas do curso de matemática, os alunos compartilharam as resoluções de problemas com os colegas através do fórum, optando por não enviar suas respostas diretamente para o tutor. $\mathrm{O}$ aluno $\mathrm{X}$ afirmou gostar dessas contribuições dos colegas, pois ajudavam a compreender alguns problemas da disciplina. $O$ aluno $\mathrm{F}$ comentou que lia as mensagens dos colegas, analisava-as e fazia comentários construtivos, no sentido de complementar a fala do colega. $O$ aluno $X$, após reavaliar a resposta sugerida pela colega com base no material de estudo, respondeu-lhe, afirmando que ela tinha razão e complementando a resposta. A aluna $\mathrm{C}$ afirmou que postagens mais detalhadas, com novos 
argumentos e ideias e que não se resumiam aos emoticons ${ }^{1}$, colaboravam para sua aprendizagem na disciplina.

Ao navegar pelo fórum, alunos avaliaram as contribuições dos colegas, criticando algumas postagens, indicando a postagem de conteúdos relevantes, bem como aquelas consideradas "sem conteúdo", em geral ignoradas no processo de navegação. Sobre esse aspecto da navegação, o aluno $X$ explicou que "a pessoa que elaborou a aula está te induzindo a ler o conteúdo e tu vai fazer um comentário em cima daquele conteúdo que tu leu, que é esse texto aqui, por exemplo, mas só que se você fizer um comentário meio fora da realidade, que às vezes acontece, né?, o pessoal coloca um comentário [crítico]".

Foram documentados dois tipos de trocas entre alunos: a primeira era voltada ao conteúdo e possuía caráter autoral (ver Figuras 1 e 2), a segunda, caráter afetivo. Sobre as do primeiro tipo, J relatou que analisava as respostas dos colegas através de pesquisas na internet, para ver se faziam sentido e se estavam de acordo com o tema. Como exemplo do segundo tipo, destaca-se a ação da Aluna $\mathrm{G}$, que elogiou o comentário do colega ao realizar um novo comentário no fórum, seguindo o que fizeram outras colegas que também o elogiaram em comentários distintos. O mesmo aconteceu com a aluna $C$, que enviou mensagem de parabéns como resposta a uma postagem de uma colega.

Essas ocorrências documentadas sobre a interação dos alunos apontam importantes ganhos no processo de aprendizagem segundo proposições teóricas e dados de estudos empíricos articulados por diversos autores. Lehtinen et al. (1999, p. 10, tradução nossa) afirmam que "uma das formas mais efetivas de colaboração está na prática do aluno explicar o material para outro [...] Webb $(1989,1992)$ descobriu que alunos que se beneficiaram mais de atividades cooperativas foram aqueles que elaboraram explicações para outros". Os resultados aqui apresentados aproximam-se de estudos de interação online de alunos adultos conduzidos por Blake e Scanlon (2012). Os pesquisadores identificaram duas categorias de interação, "reconhecer um colega ao responder ou se referir à sua postagem" e "motivando alunos, indicado pela menção de seu comprometimento individual com a tarefa do grupo" (Blake \& Scanlon, 2012, p.10). Segundo os autores, a frequência da categoria de construção colaborativa do conhecimento nesta análise indica que os alunos estão comprometidos em realizar a atividade.

1

Imagens padronizadas em geral utilizadas para expressar sentimentos diversos em mensagens em meio digital. 


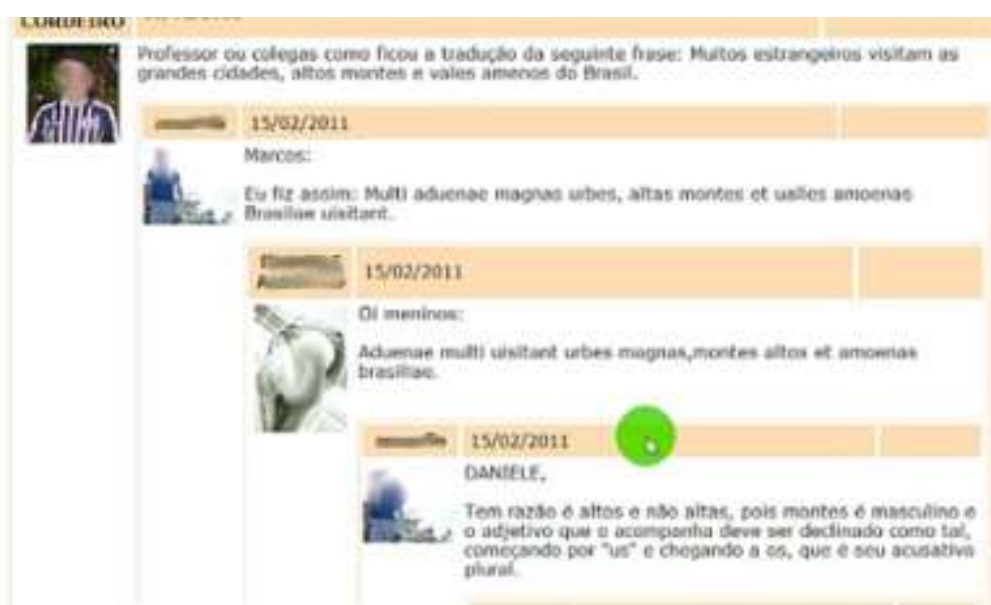

Figura 1: Alunos trocam e comparam soluções ao realizarem a atividade proposta.

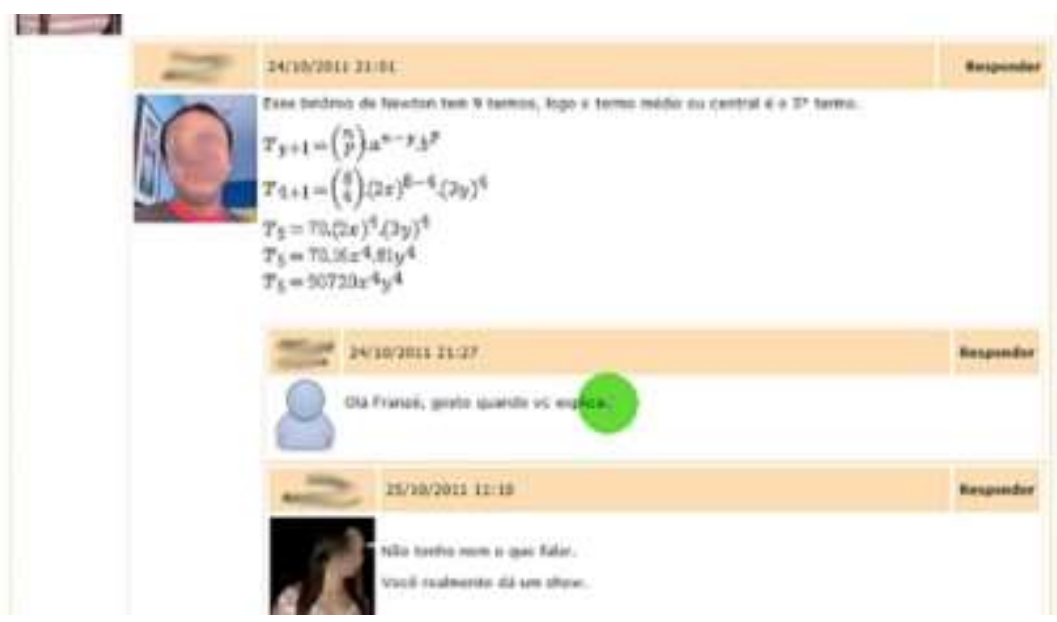

Figura 2: Alunos produzem saberes ao interagirem com colegas de turma.

Os resultados indicam um bom uso da navegação pelo AVA e pelos hipertextos, contrariando o temor de que essa navegação pudesse comprometer negativamente a aprendizagem dos alunos. Segundo Jonassen e Grabinger (1993):

[...] a aprendizagem significativa resultará do hipertexto [materiais e ferramentas no AVA] apenas se ele suportar a construção ativa de conhecimento pelos alunos ao se engajarem com ele. Acreditamos ser necessário mais do que somente um conjunto completo de links para ativar a construção do conhecimento. (Jonassen \& Grabinger, 1993, p. 15, tradução nossa).

Os autores acreditam que justamente "a aplicação mais efetiva do hipertexto é suportar a construção colaborativa do conhecimento. Ambientes de construção colaborativa do conhecimento permitem a todos os membros de uma turma ou grupo de aprendizes contribuir com suas perspectivas e interpretações" (Jonassen \& Grabinger, 1993, p. 33), ainda que ressaltem o fato de que a falta de controle do aprendiz seja uma limitação do hipertexto para a aprendizagem. Mais especificamente, cabe ressaltar o papel das propriedades interativas do fórum no AVA. Segundo 
Jonassen e Grabinger (1993, p. 26), "ambientes de aprendizagem baseados na tecnologia devem prover as necessidades de informação e de construção do conhecimento dos alunos. O aprendiz irá se engajar em trocas com o ambiente de forma incremental, ou seja, quando mais possibilidade de interação, mais elas ocorrerão".

A navegação nos fóruns indicou uma postura ativa dos alunos, que postaram comentários e arquivos direcionados aos colegas, sem prescindirem da mediação do tutor. Além de contribuir de forma decisiva para a aprendizagem desses alunos, essas ações de navegação delinearam a construção de um conteúdo novo, resultado das postagens dos alunos e dos novos arquivos inseridos no AVA. Dessa forma, a navegação pelo AVA e pelos hipertextos constituíram novas formas de aprender nas ações interativas e colaborativas dos alunos participantes desse estudo (Stahl, Koschmann \& Suthers, 2006).

\section{CONSIDERAÇÕES FINAIS}

Esse estudo analisou a emergência de novos contornos para as ações de navegação em conteúdos e materiais hipertextuais realizadas pelos alunos em seus momentos de aprendizagem. A natureza fluida e os possíveis deslocamentos dos eixos narrativos desses hipertextos, inclusive no AVA, não ocasionou significativas dificuldades para esses alunos em seu processo de aprendizagem. A documentação revelou leitura detalhada de tópicos de interesse dos alunos a fim de realizar as atividades programadas. Os procedimentos de navegação associados aos atos de errância e exploração (Centro et al. apud Padovani; Moura, 2008) não se mostraram significativos. Os hipertextos ensejaram a navegação, ainda que não linear, dos alunos com o objetivo de busca de novos conteúdos e de práticas colaborativas que contribuíram para sua aprendizagem nas disciplinas cursadas através das interações nos fóruns, aproximando-se do perfil do leitor imersivo proposto por Santaella (2004). Tais interações no fórum configuraram uma intervenção na zona de desenvolvimento proximal (Vygotsky, 2003) de alguns alunos e isso significou ganhos de aprendizagem para eles. Essas ocorrências abarcaram diversas ações, como a troca de ideias com os colegas sobre os tópicos estudados, o compartilhamento de web links e de arquivos para o estudo e a leitura linear e não linear de materiais de estudo. A categoria tarefa/comunicação (Dillenbourg et al., 1996) se constituiu como elemento central nas interações dos alunos ao configurarem práticas de aprendizagem colaborativa. Não se configuraram diferenças significativas nas ações de navegação e de aprendizagem colaborativa dos alunos das licenciaturas de matemática e de letras-português.

As ações de navegação dos alunos no AVA e para além dele e as interações entre os alunos no fórum ampliaram as fronteiras dos conteúdos das disciplinas e do papel do aluno, que se configurou como um produtor de saberes, colaborando ativamente para que colegas pudessem compreender conteúdos complexos, sem prescindir das ações prescritas do tutor. É preciso ressaltar que as evidências empíricas nas quais esse estudo se baseia referem-se a duas turmas de alunos que já haviam cursado mais da metade das disciplinas do curso de licenciatura, tendo desenvolvido habilidades para a navegação nos hipertextos para fins de estudo, bem como laços afetivos nos grupos, o que pode ter contribuído para as interações documentadas. É possível que resultados diferentes sejam obtidos com turmas com menor experiência com a navegação nos hipertextos ou 
com vínculo social e afetivo menos estabelecidos. Estudos futuros poderão elucidar tais ocorrências e eventuais diferenças nos resultados aqui apresentados.

\section{AGRADECIMENTOS}

Agradeço aos alunos bolsistas do projeto que colaboraram com as atividades de coleta e de análise de dados desse estudo. Esse estudo contou com o apoio da Fundação Cearense de Apoio ao Desenvolvimento Científico e Tecnológico (FUNCAP) e do Conselho Nacional de Desenvolvimento Científico e Tecnológico (CNPq).

\section{REFERÊNCIAS}

Blake, C., Scanlon, E. (2012). Analysing collaborative processes and interaction patterns in online discussions. Proceedings of the 8th International Conference of Networked Learning, pp. 10-17.

Braga, D. (2005). A comunicação interativa em ambiente hipermídia: as vantagens da hipermodalidade para o aprendizado em meio digital. In Marcuschi, L., Xavier, A. C. (Org.) Hipertexto e gêneros digitais. Rio de Janeiro: Lucerna, 2005.

Damiani, M. (2008). Entendendo o trabalho colaborativo em educação e revelando seus benefícios. Educar, Curitiba: Editora UFPR, N. 31, pp. 213-230.

Dillenbourg, P., Baker, M., Blaye, A., O'malley, C. (1996). The evolution of research on collaborative learning. In SPADA, Hans.; REIMAN, Peter. (Org.), Learning in humans and machine: Towards an interdisciplinary learning science. Oxford: Elsevier, pp. 189- 211.

Destefano, D., Lefevre, J. (2007). Cognitive load in hypertext reading: A review. Computers in Human Behavior, 23, pp. 1616-1641.

Jonassen, D., Grabinger, S. (1993). Applications of Hypertext: Technologies for Higher Education. Journal of Computing in Higher Education, 4(2), pp. 12-42.

Leão, L. (2001). O labirinto da hipermídia. (2 ed.). São Paulo: Iluminuras.

Lemke, J. (2001). Multimedia semiotic analysis - Focal questions. Recuperado de http://wwwpersonal.umich.edu/ jaylemke/guides/multimedia_semiotic_analysis_questions.htm.

Lemke, J. (2002). Travels in hypermodality. Visual Communication. (Vol. 1, N. 3).

Lehtinen, E., Hakkarainen, K., Lipponen, L., Rahikainen, M., Muukkonen, H. (1999). Computer Supported Collaborative Learning: A Review. Recuperado de http://www.comlab.hut.fi/opetus/205/etatehtava1.pdf.

Manovich, L. (2001). The language of new media. Cambridge, MA: The MIT Press.

Murray, J. (2003). Hamlet no Holodeck. São Paulo: Itaú Cultural: UNESP. 
Padovani, S., Moura, D. (2008). Navegação em hipermídia. Uma abordagem centrada no usuário. Rio de Janeiro: Ciência Moderna.

Primo, A. (2008). Interação mediada por computador: comunicação, cibercultura, cognição. Porto Alegre: Editora Sulina.

Santaella, L. (2004). Navegar no ciberespaço: O perfil cognitivo do leitor imersivo. São Paulo: Paulus.

Stahl, G., Koschmann, T., Suthers, D. (2006). Computer supported collaborative learning: An historical perspective. In Sawyer, R. K. (Ed.), Cambridge handbook of the learning sciences, p. 409- 426. Cambridge, UK: Cambridge University Press. Recuperado de http://GerryStahl.net/cscl/CSCL_English.pdf. 